\title{
Discussion on Construction and Innovative Strategy of Administratiors Team in Higher Educational Institutions in the View of Professionalism
}

\author{
Jin Weiwei, Yu Yongmiao \\ Langfang Teachers University, \\ Langfang, Hebei, \\ 065000 China
}

\begin{abstract}
:
the development and implementation of higher educational reform, it is imperative for the construction of administive team in higher educational institutions. At present, there are still many problems existing in administratiors team of higher educational institutions. This thesis proposes strategies of administratiors team construction in four aspects, administrator team training, implementation improvement, perfection of evaluation system and clarify of career planning, deeply discusses innovative strategies on administratiors team construction in higher educational institutions, and with the hope of that administratiors team of colleges and universities could develop in the direction of the specialization and professionalization.
\end{abstract}

KeyWords:Professionalism; Administrators

in Higher Educational Institutions; Team Construction

\section{Introduction}

With the development of society and economy, the development of higher educational institutions in China is also seeing its historic change. Specialization and professionalization of faculty have become the major problem of education need to be solved in the 21 st century. Development direction of specialization and professionalization is not only required by their team development but also trends and requires of development of higher educational institutions in China. Now two situations are created because of lacking of unformed prepotency mechanism, one is that there are enough talents but administrator team is in short supply,the other situation is that the entire quality is rather in high level but the administrator quality is not suitable for reformation and development. Therefore, it is important guarantee for colleges and universities development to explore administrator team construction in colleges and universities in the view of professionalism, establish an effective incentive mechanism, try to build up a outstanding team with "politically strong, new ideas, work hard, strong attitude, wide knowledge, discipline strict" . 
2 Current Situation of Administrator Team Construction in Higher Educational Institutions in the View of Professionalism

2.1Lack of professional background in educational management, and thinking and understanding are insufficient.

Most administrators do not have management background. Although the education background of administrators is rather high, most are not major in educational management and lack of systemic education theory study, which makes be lack of understanding and thinking to education and can not total understanding and grasp the contents and connotation of higher education. Many administrators get management experience from lower management and lack of understanding to challenge and shock of new situation. Their work seems not so active and can not modify working way and direction in time.

\subsection{Imperfection in evaluation system} makes low job performance

Evaluation of administrators' job performance is necessary for team construction and an effective way to improve recruit to administrators, and solve "difficulty in evaluation and difficulty in know people". Although there is performance evaluation system in different degree, distance of management positions and complex of management works, simple type in evaluation way, non-professional in evaluators lead that it is difficult to show up and evaluate work nature, position features and contribution for the evaluation contents. It results in the performance quality is not high and even dilatory in work and underachieves, which put off improvement of management level seriously.

\subsection{Weak in service and guidance sense} and execution ability

The management work now is more complex and policy is stronger. The service targets are more active in thinking. It requires the administrators should take requirements of students and teachers into consideration always and everywhere. Problems could be solvedshould be solved quickly and those cannot be solved should try to be solved to improve execution ability. In actual work, some administrators do their work based on experience and are not be active and patience to solve problems for service targets. The laziness makes dissatisfaction form students and teachers.

\subsection{The career planning of administrator} is not clear and circulation channel is simple.

The entire quality is rather high and most administrators have their own understanding, paying more on spiritual pursuit and self-value achievement. The development channel is not clear and it is weak in mechanism for talents choosing and employment. There is a problem of "could be up but not down, could go out but 
cannot go in" actually. If things go on like this, administrators with major strengthen is hard to change positions and their working enthusiasm will be thwarted.

\section{Countermeasures for Administrators}

\section{Team Construction of Higher Educational}

Institutions in the View of Professionalism

3.1Strengthening training and cultivation for administrators, improving ideological understanding

The development of higher education is basking in a new historical period. The management of colleges and universities faces new situation and unprecedented challenges. Strengthening the construction of colleges and universities' administratiors group is of very important practical significance for constructing harmonious campus, and training excellent socialist builder and successor. Under the influence of world multipolarization, economic globalization, society informatization and scientific and technological progress, the thoughts of teachers and students in colleges and universities are increasingly complicated, which increases the difficulty of management and puts forward higher requirement for administratiors. Therefore, in order to further improve the administratiors's ability of integrated management, communication \& cooperation and exploration \& innovation, strengthening the training and cultivation of administratiors is a must. Through multiple ways such as empathic learning, rotational communication, on-the-job training, exercise by taking a temporary post, study by being released from one's regular work and investigation trip, and devoting greater effort and investment on training of administratiors, a administratiors group with high quality is aimed to be built, so as to provide an intellectual support and organizational guarantee for science organization and effective management of school's education. Through training and cultivation, the administratiors should have a deeper understanding for the connotation and essence of higher education, and an improved professional level and specialization level.

\subsection{Perfecting evaluation system of administrators of higher educational institutions, arousing motivation and enthusiasm of work}

The establishment of an objective and fair cadre assessment and incentive mechanism is an essential guaranty ensuring successful development of each task of school, and also an effective method that arouses cadre's motivation and enthusiasm. The colleges and universities should insist the principles of placing cadres under party supervision, objective and fair, paying attention to performance, and giving attention to process and staff recognition. Assessing cadre's execution of duty and completion of work should 
beemphasized, and combine annual assessment with daily assessment, qualitative assessment with quantitative assessment, and leader assessment with mass appraisal, and continually improve the assessment and evaluation mechanism of cadre. Meanwhile, the assessment result should be linked up with social benefits and promotion, etc. of administratiors, to achieve the objective of motivation. The authority and seriousness of assessment system should be continuously enhanced, to effectively implement the assessment and evaluation system and arouse the administratiors's motivation and enthusiasm.

3.3Improving execution of administrators, strengthening their service awareness

The key of administration is implementation. The key of implementation is execution. Therefore, the construction of cadre group should place improving the execution of cadre in the first place. In case of colleges and universities, the administratiors should strictly execute relevant laws and regulations, have the tenacity and patience of implementation, have an endlessly enthusiasm, and guarantee the efficiency of advance. Reflecting in work, execution refers to completing work task as per quality, quantity and time. In addition, the service awareness should be continually improved. Conditions of "High threshold, Terrible look, Unpleasant word, Difficult completion" should be completely eradicated.

\subsection{Clarifying vocational development} planning of administrators, widening circulation channel of administrators

Since the management team of higher educational institutions decides the future and destiny of colleges and universities, clarifying vocational development planning of administrators through professional and specialization path is of great significance. This path will make the colleges and universities' administratiors establish the concepts of attaching importance to post, making light of position, attaching importance to intelligence, making light of qualifications and record of service, attaching importance to ability and making light of power, and this will powerfully promote the enthusiasm of administratiors. The staff system of education can also be used to straighten out the internal personal connection of colleges and universities, and standardize internal management. After traditional lifelong tenure of post is broken by post appointment and post assessment, etc., the competitive mechanism will be much obvious. In addition to clarifying vocational development planning, the circulation channel and development space of administratiors will be further broadened. 
4Innovative strategies for Administrators Team Construction of Higher Educational Institutions in the View of Professionalism

4.1Strengthening construction of campus culture, enhancing cohesion of administratiors group

The concept of campus culture is the concentrated reflection of spiritual culture of colleges and universities, which can roundly reflect the values and standard of moral behavior of colleges and universities. The construction of campus culture can further perfect internal construction of organization, student management, improve students' comprehensive quality and enhance administratiors group's cohesion. Various tasks faced by colleges and universities need the tight cooperation of cadres, the close join of departments, the close communication of superior and subordinate. It won't work out without the consciousness of unity and cohesion. Therefore, enhancing cohesion through campus culture construction is the priority among priorities in cadre group construction.

\subsection{Selecting administratiors utilizing} employment ideality of enterprise

Talent is the core competitiveness of enterprise. For colleges and universities, the selection and training of administratiors are of great significance. The selection process of administratiors certainly will have a great influence on the development of school. In the selection process, the competency feature model should be established firstly. The competency features generally include lofty ambitions and aspirations, noble personality charm, excellent execution and strong service awareness, etc. In terms of selection mode, the theoretical knowledge of talent quality test can be referred to, and the difficulty of assessment can be suitably increased. For instance, psychological test, administratiors ability test, scenario simulation analysis, in-basket processing, leaderless group discussion and election speech, etc. can be set, to ensure fair, objective, scientific and reasonable selection process.

\subsection{Establishing a learning-type administratiors group}

For colleges and universities, in order to establish a learning-type administratiors group, the initiative and creativity of each teacher should be fully motivated, to make the administratiors establish the concept of lifelong learning, continually innovate working ideas and working method, exert the creativity of collective and improve the management level of colleges and universities. However, learning is a progressive process. Important reasons for job burnout of colleges and universities' administratiors presently include lacking of timely system training and guidance, low professional quality, improper working method, 
unreasonable time distribution and not obvious working effect. Therefore, advanced management concept of learning-type enterprise should be utilized to draw up a career planning for administratiors, help them to depict a career blueprint, maintain the youthful spirit and vigor of administratiors team, and improve the overall cohesion and fighting capacity of organization.

\subsection{Improving working mode of} administratiors by utilizing concept of project management

Project management refers to that various knowledge, skills, means and methods are utilized in the operation process of project to make the project achieve or exceed the expected objective with limited resources. It can help us better solve the problems encountered in project, optimize human resource allocation, lower the cost of activity and maximize the benefits. In terms of colleges and universities, the project management mode can reduce the link and bug of management activity of colleges and universities, and improve level and status of administratiors work. It can also facilitate the communication and cooperation of cadres, strengthen their consciousness of competition and innovation, improve their ability of organization, management, decision-making and judgment, and further improve the operation effect and efficiency of colleges and universities.

\section{Conclusion}

In this paper, we discuss on construction and innovative strategy of administratiors team in higher educational institutions in the view of professionalism. This research proposes strategies of administratiors team construction in the following aspects, administrator team training, implementation improvement, the perfection of evaluation system and the schedule of career planning. For colleges and universities, in order to establish a learning-type administratiors group, the initiative and creativity of each teacher should be fully motivated. Various tasks faced by colleges and universities need the tight cooperation of cadres, the close join of departments, the close communication of superior and subordinate. We believe that through the implementation of the proposed framework the performance will be better.

\section{ACKNOWLEDGEMENTS:}

Fund Project: Scientific Research Project of Langfang Teachers University,Construction and Innovative Strategy of Administratiors Team in Higher Educational Institutions from Perspectiver of Scientific Development Concept, Project No. LFWY201515

\section{References}

[1]. Liu Wengang. Thoughts on Strengthening the Construction of Colleges and Universities' 
Administratiors Group [J]. Time Education, 2012(19)

[2]. Xu Hui, Ji Zhizhou. Thoughts on Constructing High-quality Management Team by Colleges and Universities in New
Situation [J]. Chinese Higher Education, 2010(5)

[3]. Gan Derong. Thoughts on Strengthening the Construction of Administratiorss in Colleges and Universities in the New Situation [J]. Social Sciences Review, 2012(5) 